\title{
УДК:631.52:633.111:575.22 \\ https://doi.org/10.53040/gppb7.2021.44 \\ ИЗУЧЕНИЕ ПОЛИМОРФИЗМА ЭСТЕРАЗНЫХ ИЗОФЕРМЕНТОВ В СЕМЕНАХ КАРТИРУЮЩЕЙ ПОПУЛЯЦИИ ЯРОВОЙ МЯГКОЙ ПШЕНИЦЫ
}

\author{
Рудакова Анжела ${ }^{1}$ Рудаков Сергей ${ }^{1}$, Чесноков Юрий \\ ${ }^{1}$ Государственный университет Молдовы, Кишинэу, Республика Молдова \\ e-mail: rud-as@mail.ru \\ ${ }^{2}$ ФББНУ "Агрофизический научно-исследовательский институт", С.-Петербург, Россия \\ e-mail: yuv_chesnokov@agrophys.ru
}

\begin{abstract}
Using electrophoresis, in 114 recombinant hybrid lines of the mapping population of spring bread wheat and in 2 parental forms, 7 esterase isoenzymes were found: A1-A7 ( $\mathrm{M}_{\mathrm{r}}$ 93-138 $\left.\mathrm{kDa}\right)$. According to their esterase composition, all samples were subdivided into 17 zymotypes. Isoforms A4 and A6 are present in all zymotypes, i.e. are monomorphic. The other 5 isozymes provide a high level of polymorphism in the population. The majority of genotypes belong to the zymotype Gr. 1 (27\%), which includes 6 isoforms. Among them there are isoforms A1 and A7, characteristic only for each of the parent forms, which indicates the codominant inheritance of these isoenzymes.
\end{abstract}

Key words: isoforms, esterases, soft wheat, zymotypes, polymorphism.

\section{Введение}

Отбор селекционного материала по фенотипическим признакам требует значительных затрат. Более удобным методом оценки генетического материала может служить анализ при помощи биохимических маркеров. Электрофоретические методы предоставили большое количество ценных генетических маркеров для классических генетических исследований цветковых растений. $[1,2]$.

Исследование полиморфного электрофоретического спектра изоферментов - удобный метод экспресс оценки генетического разнообразия растений [3]. Такими биохимическими генетическими маркерами могут успешно служить неспецифические эстеразы [4].

Целью данного исследования было изучить полиморфизм изоферментного состава эстераз зрелых семян рекомбинантных гибридных линий яровой мягкой пшеницы для последующего анализа QTL.

\section{Материалы и методы}

В качестве материала для исследований были взяты зрелые семена 2-х родительских форм, синтетический гексаплоид W7984 и Opata 85, а также их 114 рекомбинантных гибридных линий картирующей популяции яровой мягкой пшеницы $[5,6]$.

Ферменты экстрагировали из муки семян в соотношении 1:2 при помощи экстрагирующего буфера (0,005 M Tрис-HCl, $\mathrm{pH} 8,3)$ в присутствии $0,002 \mathrm{M} \mathrm{MgCl} 2$ и $10 \%$ глицерина, в течение 10 часов при $4^{0} \mathrm{C}$. Затем гомогенаты центрифугировали при 15тыс. об./мин, 5 мин, отбирали надосадочную жидкость и использовали ее для электрофоретического анализа $[7,8]$.

Электрофорез проводили в системе ПААГ с концентрациями разделяющего геля - $8 \%$ и концентрирующего - 4\%, при 5-8 $8^{0}$, силе тока - $20 \mathrm{~mA}$, в течение 2,5 часов. В каждый трек вносили по 15 мкл экстракта. Для электрофореза использовали камеру Mini-PROTEAN Tetra Cell (Bio-Rad Laboratories, USA).

Для обнаружения изоферментов гель после окончания электрофореза обрабатывали реактивом на неспецифическую эстеразу в течение 15-30 минут до проявления зон [9]. Для сканирования полученных зимограмм применяли сканер Epson Expression 10000XL (GEHealthcare, CША). При помощи программы Phoretix 1D Advansed (Total Lab, Ltd., Великобритания) был проведен расчет количественного соотношения всех зон в треках и рассчитаны молекулярные массы изоферментов.

\section{Результаты и обсуждение}

При помощи электрофореза у 114 рекомбинантных гибридных линий картирующей популяции яровой мягкой пшеницы и в 2-х родительских формах - W7984 и Opata 85, было обнаружено 7 основных изоферментов эстераз с молекулярными массами от 93 кДа до 138 кДа (рис.1), условно обозначенных далее А1-А7 (Табл.1, 2). 


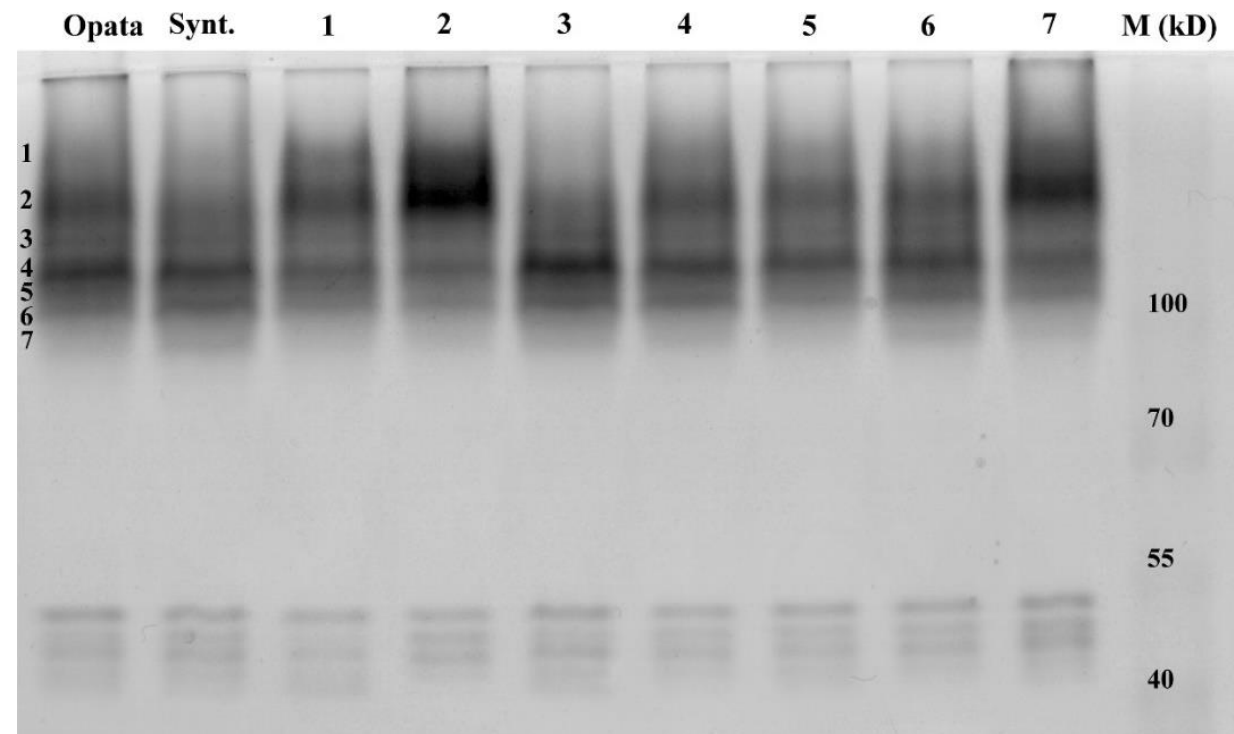

Рис. 1. Зимограммы изоферментов эстераз зрелых семян рекомбинантных гибридных линий картирующей популяции яровой мягкой пшеницы. Слева наверху - родительские формы: Opata 85 и Synt. (синтетический гексаплоид W7984). Далее сверху - номера генотипов в картирующей популяции, цифры слева вниз - изоформы эстераз. Справа вниз приведены маркеры молекулярных масс.

По составу эстеразных изоферментов изученные образцы были подразделены на 17 зимотипов (Табл.1, Табл.2).

Родительская форма Opata 85 характеризуется наличием 6 изоферментов: A1-A6. В родительской форме W7984 выявлены изоферменты A2-A4, A6-A7 (Табл.1). Таким образом, эстеразы A1 и A5 специфичны только для родительской формы Opata 85, в то время как эстераза A7 - только для формы W7984, что позволяет характеризовать распределение родительских признаков в картирующей популяции.

Эстеразные изоформы А4 и А6 присутствуют в составе всех зимотипов, т.е. являются мономорфными. Зоны изоферентов А2 (частота встречаемости 96,5\%), A3 (81,6\%), A7 (62.3\%) и A1 (57\%) в наибольшей степени определяют полиморфизм исследуемой популяции по изоформам эстераз.

Таблица 1. Распределение эстеразных зон среди зимотипов пшеницы

\begin{tabular}{|c|c|c|c|c|c|c|c|c|}
\hline Зимотип & $\begin{array}{c}\mathrm{A} 1 \\
138 \mathrm{kDa}\end{array}$ & $\begin{array}{c}\mathrm{A} 2 \\
129 \mathrm{kDa}\end{array}$ & $\begin{array}{c}\mathrm{A} 3 \\
120 \mathrm{kDa}\end{array}$ & $\begin{array}{c}\mathrm{A} 4 \\
113 \mathrm{kDa}\end{array}$ & $\begin{array}{c}\mathrm{A} 5 \\
108 \mathrm{kDa}\end{array}$ & $\begin{array}{c}\mathrm{A} 6 \\
106 \mathrm{kDa}\end{array}$ & $\begin{array}{c}\mathrm{A} 7 \\
93 \mathrm{kDa}\end{array}$ & $\begin{array}{c}\text { Общее чис- } \\
\text { ло зон }\end{array}$ \\
\hline Гp.1 & + & + & + & + & & + & + & 6 \\
\hline Гр.2 (W7984) & & + & + & + & & + & + & 5 \\
\hline Гр.3 & + & + & + & + & & + & & 5 \\
\hline Гр.4 & & + & + & + & + & + & + & 6 \\
\hline Гр.5(Opata) & + & + & + & + & + & + & & 6 \\
\hline Гр.6 & & + & + & + & & + & & 4 \\
\hline Гр.7 & & + & & + & & + & & 3 \\
\hline$\Gamma \mathrm{p} .8$ & + & + & & + & & + & + & 5 \\
\hline Гр.9 & + & + & + & + & + & + & + & 7 \\
\hline Гр.10 & + & + & & + & & + & & 4 \\
\hline Гр.11 & + & + & & + & + & + & & 5 \\
\hline Гр.12 & & & + & + & + & + & & 4 \\
\hline Гр.13 & & + & & + & + & + & & 4 \\
\hline Гр.14 & & + & & + & & + & + & 4 \\
\hline Гр.15 & & & + & + & & + & + & 4 \\
\hline Гр.16 & & + & & + & + & + & + & 5 \\
\hline Гр.17 & & + & + & + & + & + & & 5 \\
\hline Частота (шт) & 65 & 110 & 93 & 114 & 31 & 114 & 71 & \\
\hline Частота зоны(\%) & 57.0 & 96.5 & 81.6 & 100 & 27.2 & 100 & 62.3 & \\
\hline
\end{tabular}


Два зимотипа - Гр.2 и Гр.5 - по составу изоформ эстераз полностью соответствуют родительским формам W7984 и Ората 85, соответственно (Табл. 2). В 16-ти из исследованных генотипов был обнаружен эстеразный состав по типу W7984, что составляет 14\% всей популяции, эстеразный комплекс по типу Opata 85 был выявлен у 9 генотипов (7,9\%).

Для большинства генотипов (27,2 \%) характерен зимотип Гр.1, в состав которого входят 6 изоформ, в том числе изоформы А1 и А7, характерные только для каждой из родительских форм, что свидетельствует о кодоминантом наследовании этих изоферментов.

Единственный зимотип Гр.9, содержащий все 7 изоформ эстераз, характерен лишь для 4 генотипов (3,5\%). Наименьшее количество зон - 3 изоформы эстераз, содержит зимотип Гр.7, который представлен в $9 \%$ популяции. Зимотипы Гр.10 - Гр.17 содержат по 4-5 эстеразных изофермента, эти зимотипы очень редки - $0.9-2.6 \%$.

Таблица 2. Зимотипы семян пшеницы и их эстеразный состав

\begin{tabular}{|c|c|c|c|c|c|}
\hline Зимотип & Зоны эстераз" & $\begin{array}{l}\text { Число зон в } \\
\text { зимотипе }\end{array}$ & Номера генотипов & $\begin{array}{l}\text { Всего ге- } \\
\text { нотипов }\end{array}$ & $\%$ \\
\hline Гр.1 & A1-A4, A6-A7 & 6 & $\begin{array}{c}4,6,7,10,15,17,20,24,25,27,30- \\
34,37,38,41,44,45,47,63,82,83 \\
85,87,90,101,106,109,113\end{array}$ & 31 & 27.2 \\
\hline Гр.2 & A2-A4, A6-A7 & 5 & $\begin{array}{c}3,13,22,26,36,42,48,77 \\
79,80,84,88,91-93,102\end{array}$ & 16 & 14.0 \\
\hline Гр.3 & $\mathrm{A} 1-\mathrm{A} 4, \mathrm{~A} 6$ & 5 & $2,5,19,21,43,46,50,62,68,69,81$ & 11 & 9.6 \\
\hline$\Gamma \mathrm{p} .4$ & A2-A7 & 6 & $23,28,39,54,55,60,70,74,76,105$ & 10 & 8.8 \\
\hline Гр.5 & A1-A6 & 6 & $1,14,35,52,53,64-66,73$ & 9 & 7.9 \\
\hline Гр.6 & $\mathrm{A} 2-\mathrm{A} 4, \mathrm{~A} 6$ & 4 & $40,59,75,94,96-98$ & 7 & 6.1 \\
\hline Гр.7 & $\mathrm{A} 2, \mathrm{~A} 4, \mathrm{~A} 6$ & 3 & $12,71,99,100,103,104$ & 6 & 5.3 \\
\hline Гр.8 & $\mathrm{A} 1-\mathrm{A} 2, \mathrm{~A} 4, \mathrm{~A} 6-\mathrm{A} 7$ & 5 & $16,72,86,111,115$ & 5 & 4.4 \\
\hline Гр.9 & A1-A7 & 7 & $29,51,56,57$ & 4 & 3.5 \\
\hline Гр.10 & $\mathrm{A} 1-\mathrm{A} 2, \mathrm{~A} 4, \mathrm{~A} 6$ & 4 & $49,107,110$ & 3 & 2.6 \\
\hline Гр.11 & $\mathrm{A} 1-\mathrm{A} 2, \mathrm{~A} 4-\mathrm{A} 6$ & 5 & 9,78 & 2 & 1.8 \\
\hline Гр.12 & A3-A6 & 4 & 67,112 & 2 & 1.8 \\
\hline Гр.13 & A2, A4-A6 & 4 & 11,58 & 2 & 1.8 \\
\hline Гр.14 & $\mathrm{A} 2, \mathrm{~A} 4, \mathrm{~A} 6-\mathrm{A} 7$ & 4 & 89,108 & 2 & 1.8 \\
\hline Гр.15 & $\mathrm{A} 3-\mathrm{A} 4, \mathrm{~A} 6-\mathrm{A} 7$ & 4 & 18,95 & 2 & 1.8 \\
\hline Гр.16 & A2, A4-A7 & 5 & 8 & 1 & 0.9 \\
\hline Гр.17 & A2-A6 & 5 & 114 & 1 & 0.9 \\
\hline
\end{tabular}

В образцах исследуемой популяции количественное соотношение отдельных изоферментов значительно варьирует. Минимальное содержание было обнаружено для зоны А7 - 3.4 \%, максимальное количество было выявлено для зоны А2 - 65.4\% (табл.3). Среднее значение отдельных эстеразных зон во всей популяции колебалось от 7.85\% (зона А5) до 31.5\% (зона А2).

Таблица 3. Количество изоформ эстеразных ферментов в семенах пшеницы

\begin{tabular}{|c|c|c|c|c|c|c|c|}
\hline Зона изофермента & $\mathbf{A 1}$ & $\mathbf{A 2}$ & $\mathbf{A 3}$ & $\mathbf{A 4}$ & $\mathbf{A 5}$ & $\mathbf{A 6}$ & $\mathbf{A 7}$ \\
\hline $\mathrm{M}_{\text {г } \text { (кДа) }}$ & $\mathbf{1 3 8}$ & $\mathbf{1 2 9}$ & $\mathbf{1 2 0}$ & $\mathbf{1 1 3}$ & $\mathbf{1 0 8}$ & $\mathbf{1 0 6}$ & $\mathbf{9 3}$ \\
\hline Мин. \% в популяци & 8.48 & 15.24 & 7.44 & 14.65 & 4.75 & 6.92 & 3.43 \\
\hline Мах. \% в популяции & 35.17 & 65.41 & 23.89 & 48.05 & 14.06 & 30.47 & 28.72 \\
\hline Среднее значение & 16.37 & $\mathbf{3 1 . 5 0}$ & 11.73 & $\mathbf{2 4 . 1 3}$ & 7.85 & 17.09 & 11.63 \\
\hline
\end{tabular}

\section{Выводы}

В семенах рекомбинантных гибридных линий яровой мягкой пшеницы был обнаружен значительный полиморфизм изоферментного состава эстераз. Интересно, что наличие 7 изоформ эстераз обеспечивает значительное количество зимотипов - 17, с высоким уровнем полиморфизма как по наличию и относительному количеству изоформ, так и по представительности этих зимотипов в исследованной картирующей популяции. 


\section{Литература}

1. TANKSLEY, S.D., RICK, C.M. Isozyme gene linkage map of the tomato: Applications in genetics and breeding // Theor. Appl. Genet.- 1980. - Vol. 57. - P. 161-170.

2. GOMEZ, C., SAENZ DE MIERA, L., Perez de la Vega, M. Estimation of the isozymatic genetic variability of Spanish Avena sativa germplasm collection // Plant Breed. - 1991. - Vol. 106. - P. 293-300.

3. BROWN, A.H., CLEGG, M.T. Isozyme assessment of plant genetic resources // Isozymes Curr. Top. Biol. Med Res. - 1983. - Vol. 11. - P. 285-295.

4. РУДАКОВА, А.С., РУДАКОВ, С.В., АРТЕМЬЕВА А.М., КУРИНА, А.Б., КОЧЕРИНА, Н.В., ЧЕСНОКОВ, Ю.В. Изучение полиморфизма эстеразного состава зрелых семян образцов редиса (Raphanus sativus L.) коллекции ВИР // Овощи России. - 2017. - Vol. 5(38). - С. 3-8.

5. ЧЕСНОКОВ, Ю.В., ПОЧЕПНЯ, Н.В., КОЗЛЕНКО, Л.В., СИТНИКОВ, М.Н., МИТРОФАНОВА, О.П., СЮКОВ, В.В., КОЧЕТКОВ, Д.В., ЛОВАССЕР, У., БЁРНЕР, А. Картирование QТL, определяющих проявление агрономически и хозяйственно ценных признаков у яровой мягкой пшеницы (Triticum aestivum L.) в различных экологических регионах России // Вавиловский журнал генетики и селекции. - 2012. Т.16 (№4/2). - С.970-986.

6. ЧЕСНОКОВ, Ю.В., СИТНИКОВ, М.Н., ШУМЛЯНСКАЯ, Н.В., КОЧЕРИНА, Н.В., ГОНЧАРОВА, Э.А., КОЗЛЕНКО, Л.В., СЮКОВ, В.В., КОЧЕТКОВ, Д.В., ЛОВАССЕР, У., БЁРНЕР, А. Рекомбинантные инбредные линии картирующей популяции ITMI яровой мягкой пшеницы Triticum aestivum L. (экологогеографические испытания и картирование QTL). Каталог мировой коллекции ВИР. СПб: ВИР., 2013. Вып. 813. - 68 c.

7. ORNSTEIN L. Disc electrophoresis: background and theory. // Anal. NY Acad. Sci. - 1964. - Vol. 121. - P. 321-349.

8. DAVIS, B.J. Disc electrophoresis. II. Method and application to human serum proteins // Annals of the NY Academy of Science. - 1964. - Vol. 121. - P. 404-427.

9. MEON, S., Protein, esterase and peroxidase patterns of phytophtora isolates from Cocoa in Malaysia // J. Islamic Acad. Sci. - 1988. - Vol.1(2). - P. 154-158. 